\title{
BIOGRAFIA, GENEALOGIA E TEORIA DAS ELITES. MAPEANDO CARACTERÍSTICAS DO PODER LOCAL
}

\section{Alessandro Cavassin Alves ${ }^{1}$}

Resumo: Este trabalho busca relacionar duas possibilidades metodológicas, a biografia e a genealogia, para compreender um aspecto da política brasileira, que é a constituição da sua elite política. Para tanto, foi realizado um levantamento biográfico e genealógico de Joaquim Severo Corrêa (1833-1875), deputado provincial do Paraná na segunda metade do século XIX, morador em uma colônia para imigrantes denominada de Assunguy, localizada a $106 \mathrm{~km}$ de Curitiba, Paraná. A biografia e a genealogia podem contribuir muito nestas discussões. Enfim, o que se irá perceber através de um "estudo de caso", é que tais indivíduos, denominados de "elites", possuem, constroem ou mesmo reproduzem "recursos" que os colocam em posição de vantagem em relação aos demais membros desta sociedade, se perpetuando e se adaptando, por vezes, por gerações.

Palavras-Chave: biografia, genealogia, teoria das elites.

Resumen: Este trabajo pretende relacionar dos posibilidades metodológicas, la biografía y la genealogía, para entender un aspecto de la política brasileña, que es la constituciónde su élite política. Con ese fin, hemos realizado una encuesta de la biográfica ygenealógica Severo Joaquim Correa (1833-1875), diputado provincial de Paraná, en la segunda mitad del siglo XIX, que vive en una colonia llamada para Assunguyinmigrantes, que se encuentra a $106 \mathrm{~km}$ de Curitiba, Paraná. La biografía y la genealogía puede contribuir mucho en estas discusiones. De todos modos, lo que se verá a través de un "estudio de caso" es que estas personas, llamadas "elites"tienen, construir o incluso reproducir los "recursos" que los pone en una ventaja sobre los demás miembros de esta sociedad, la perpetuación y la adaptación, a veces durante generaciones.

Palabras-claves: biografía, genealogía, teoría de las élites.

Abstract: This work seeks to relate two methodological possibilities, biography and genealogy,to understand an aspect of Brazilian politics, which is the constitution of its political elite. To that end, we conducted a survey of biographical and genealogical SeveroJoaquim Correa (1833-1875), Deputy Provincial of Paraná in the second half of the nineteenth century, living in a colony called for immigrants Assunguy, located 106 kmfrom Curitiba, Parana. The biography and genealogy can contribute a lot in thesediscussions. Anyway, what will be seen through a "case study" is that such individuals, called "elites" have, build or even reproduce "resources" that put them at an advantage over other members of this society, perpetuating and adapting,sometimes for generations.

Key-words: biography, genealogy, theory of elites.

\footnotetext{
${ }^{1}$ Doutorando em Sociologia pela UFPR (2010-2013). Linha de Pesquisa: Instituições e Poder; Bolsista
} REUNI; Mestre em Sociologia e Graduação em Ciências Sociais pela UFPR. Professor. 


\section{INTRODUÇÃO}

Este trabalho busca relacionar duas possibilidades metodológicas, a biografia e a genealogia, para compreender um aspecto da política brasileira, que é a constituição da sua elite política.

Para tanto, foi realizado um levantamento biográfico e genealógico de Joaquim Severo Corrêa (1833-1875), deputado provincial do Paraná na segunda metade do século XIX, morador em uma colônia para imigrantes denominada de Assunguy, localizada a 106 km de Curitiba, Paraná.

Verificar a trajetória de vida deste indivíduo possibilita discutir pontos importantes na teoria das elites, como a constituição de seus recursos sociais, econômicos e simbólicos em uma determinada localidade e contexto histórico, e ainda, sua origem social e rede de parentesco, envolvendo períodos de longa duração.

A biografia limita-se ao modelo cronológico/linear construído a partir de fontes oficiais, levantando dados de um "homem público", e, ao mesmo tempo, buscase contextualizar histórica e geograficamente onde este ator vive. A genealogia deste indivíduo, por sua vez, permitirá uma análise coletiva desta “elite dirigente”, propondo que as "famílias superiores na classe dominante há várias gerações formam complexas redes sociais, redes políticas e redes de nepotismo, profundamente inseridas no tempo e nos cargos do aparelho de Estado" (OLIVEIRA, 2011).

Preocupações estas presentes nos precursores da teoria das elites, como Gaetano Mosca e Vilfredo Pareto. Para o primeiro, esta minoria, chamada de classe política, tinha como característica a organização e se destacava por possuir méritos e dons reconhecidos pela maioria governada, como força física, o contato direto com divindades, o saber, a riqueza, etc. E ainda, a existência de forças sociais que distinguem governantes de governados, como exemplo, o nascimento, a riqueza, o valor militar. Para Mosca, a classe política ao se estabilizar busca manter assim as posições alcançadas e garantir esta sucessão a seus descendentes. Pareto, para quem os homens são naturalmente desiguais, chamou de elites "aqueles que fazem parte do grau superior”, em especial por possuírem algum dom ou qualidade, formando a elite política ou a aristocracia. Uma aristocracia significaria os melhores em cada atividade; mas as aristocracias não são eternas. Na verdade, a história, na formulação consagrada de Pareto, seria um "cemitério de aristocracias". Daí a questão da "circulação das elites", que para este autor, asseguraria o equilíbrio e a longevidade do corpo social (GRYNSZPAN, 1996, 1999; BOBBIO, 2004).

A biografia e a genealogia podem contribuir muito nestas discussões. Enfim, o que se irá perceber através de um “estudo de caso”, é que tais indivíduos, denominados 
de "elites", possuem, constroem ou mesmo reproduzem "recursos" que os colocam em posição de vantagem em relação aos demais membros desta sociedade, se perpetuando e se adaptando, por vezes, por gerações.

\section{BIOGRAFIA, GENEALOGIA E TEORIA DAS ELITES}

Quanto à teoria das elites, de antemão se sabe da dificuldade de se conceituar o termo. Mas o conceito "elites” é importante por destacar a clássica ideia de que:

Em qualquer sociedade, em qualquer grupo, em qualquer época ou lugar, havia sempre uma minoria, uma elite que, por seus dons, e sua competência e seus recursos, se destacava e detinha o poder, dirigindo a maioria. Esta era uma lei sociológica inexorável, que nem mesmo o mecanismo do sufrágio universal era capaz de romper (GRYNSZPAN, 1999, p.9).

Entretanto, também se percebe que o estudo de "elites" remete a um amplo leque de questões e pesquisa:

O fundamental para o estudo das minorias que dominam uma dada comunidade seria, então, a investigação da origem social de seus membros, o modo de constituição da autoridade desse grupo, os recursos (sociais, econômicos e simbólicos) que seus membros controlam e comandam, como e em que grupos sociais os indivíduos que fazem parte desse grupo minoritário são recrutados, quais as instituições que abrigam os grupos dominantes de dada comunidade, como se desenvolve a relação desse grupo com os governados etc. As respostas a essas questões revelariam informações importantes acerca da natureza e das disposições dos indivíduos que detêm o poder político e que são responsáveis pelas decisões que afetam o destino de toda comunidade (PERISSINOTTO [et.al.], 2007, p.32).

Da mesma forma, Flávio HEINZ (2006, p.o6-08) reconhece que "o termo elite aponta tão-somente para uma 'vasta zona de investigação científica cobrindo profissionais da política, empresários, legisladores etc., e não evoca nenhuma implicação teórica particular". Mas, a noção "elite” nos possibilita visualizar os grupos de indivíduos que ocupam posições chaves em uma sociedade e que dispõem de poderes, influência e privilégios inacessíveis ao conjunto de seus membros.

Portanto, o que se quer entender desta elite que se verifica existir?

Neste sentido, aqui se buscou selecionar um indivíduo de destaque numa pequena localidade paranaense, a partir da metade do século XIX, e assim, mapear suas características biográficas para se compreender o que o diferencia dos demais atores sociais nesta mesma localidade, proporcionando a ele, por exemplo, chegar a ser deputado provincial. 
Quanto à questão metodológica, a biografia será utilizada nesta reconstrução social. Joaquim Severo Corrêa era um homem público e os registros oficiais vão apresentando suas conquistas, de forma cronológica. As principais fontes são os relatórios dos presidentes da província do Paraná, o jornal Dezenove de Dezembro, os diários oficiais do Império brasileiro, os relatórios de diretores da colônia do Assunguy, ambos abrangendo o tempo de sua vida; e mais, o relatório do cônsul inglês G. Lennon Hunt de 1874 e o livro de relato de viagem do inglês Bigg-Whiter, publicado em 1878. Tais documentos revelaram a trajetória pública deste indivíduo.

Com isto, os documentos oficiais possibilitam perceber os mecanismos que Severo Corrêa dispunha para se destacar como membro de uma elite local. Primeiro por pertencer a guarda nacional e ter sido nomeado em suas inúmeras patentes durante toda sua vida. Segundo por ter acesso a recursos econômicos, enquanto comerciante e empreiteiro em obras públicas onde vivia. E de 1861 a 1875, se verifica como ele foi se apropriando significativamente de terras destinadas a colonos. E a sua eleição para deputado provincial a partir de uma colônia de imigrantes, demonstra sua forte liderança em toda a região norte de Curitiba.

A presente biografia, como dito, limita-se ao que foi encontrado em alguns documentos oficiais, sem a pretensão da busca exaustiva de outras fontes primárias, na qual seria ideal para ampliar a compreensão sobre suas atividades reais. Considera-se também aqui a crítica de Pierre Bourdieu (1986) quanto à "ilusão biográfica" que uma sequência de fatos sobre um indivíduo isolado de seu campo e relações pode causar; mas, acredita-se que o objetivo de mapear as características gerais da constituição do poder de um membro da elite local, representada pelo poder econômico, político e militar foi alcançada através destes documentos.

Outro problema é ser esta uma biografia que não trata de sua personalidade, vida privada, relacionamentos familiares, aparência, costumes, valores, por que não teve filhos, motivo de sua morte prematura etc. Não se pretende saber também como ele agia em suas atividades de comércio, com seus empregados, como membro da guarda nacional e como político. Com isto ficam de fora desta análise aspectos importantes para a teoria das elites, que são entender os valores da elite, ou mesmo buscar analisar concretamente processos decisórios para avaliar a real capacidade de Severo Corrêa de impor suas vontades ou de seu grupo, e mesmo qual era seu perfil ideológico.

Outra opção metodológica deste trabalho foi a genealogia. Aparentemente, genealogia e biografia poderiam não ser compatíveis numa mesma análise. Afinal, a genealogia pretende ser um estudo de caráter de longa duração, diferente do mediado pela análise micro e de curta duração que é uma biografia. Porém, ao se levantar a 
biografia pública de Severo Corrêa, numa pequena localidade paranaense, logo se percebeu que ele era membro de extensas e tradicionais famílias paranaense. Sua origem social foi revelada pelo estudo genealógico. E será a genealogia que possibilitará supor que a concretização de suas conquistas foram também possíveis principalmente por ser ele membro de tradicionais famílias paranaenses detentoras do poder econômico e político nesta província.

Gaetano Mosca, na Itália do final do século XIX, argumentava que "qualquer indivíduo que faça parte da classe política deve ter, ou pelo menos presume-se que tenha, um mérito ou uma qualidade que não são possuídos por todos, aos quais, na sociedade em que vivemos, à maioria dos homens confere uma grande importância”. E um destes méritos é o de ter nascido em uma família capaz de lhe proporcionar riqueza, educação, relações sociais, contatos, que dificilmente uma outra pessoa conseguiria.

\begin{abstract}
Nascimento, significa riqueza, significa relações que alguém pode facilmente adquirir, o que poderá ser extremamente difícil para uma outra pessoa; nascimento significa facilidade relativa de tornar-se dono de certos conhecimentos que, para outras pessoas, custarão muito estudo; nascimento significa dizer estar acostumado ao comando e ocupar uma posição importante; estas últimas coisas, geralmente julgadas de pouco peso, têm, ao contrário, uma enorme importância na prática da sociedade. O manto é oferecido a todos, todos podem tentar ganhá-lo, ainda que alguns deles distem três passos e outros distem 100. Eis como o nascimento é determinante.

A experiência histórica não faz senão confirmar aquelas induções que podem ser tiradas pela sociedade atual. Existem muitos casos nos quais os cargos eletivos ficaram quase sempre enquistados nas mesmas famílias, porque naturalmente quem nasce fora delas terá de superar muitas desvantagens para poder concorrer vitoriosamente (MOSCA, 1925, in: GRYNSZPAN, 1999, p.83).
\end{abstract}

Aqui, acredita-se que a genealogia pode ampliar a reflexão sobre a força social do "nascimento". De acordo com Ricardo Costa de Oliveira (2001, p.16), a genealogia auxilia a análise política das famílias históricas, permitindo revelar histórias reais das gerações navegando no tempo. E ainda:

\footnotetext{
[A genealogia] permite a análise temporal dos itinerários familiares ao longo dos séculos. Esta disciplina auxiliar informa sobre a gênese e os processos constitutivos de grupos familiares cujas formações primárias podem ser lidas, traduzidas e convertidas, desde que a coleta de dados seja orientada a partir de teorias críticas, em bases para o estabelecimento das classes sociais como totalidades vivas, compostas de homens e mulheres reais na história em suas efetivas relações sociais (OLIVEIRA, 2001, p.19).
}

Para o Paraná, os estudiosos da classe dominante regional têm o imenso privilégio de possuir uma vasta literatura genealógica sobre sua elite, que é a Genealogia Paranaense, obra de Francisco Negrão, em seis volumes. Uma fonte muito 
rica quando se quer saber as relações de parentesco na história paranaense, anterior ao início do século XX (OLIVEIRA, 2001, p.33, nota 22). Fonte genealógica utilizada neste trabalho para entender as relações familiares de Severo Corrêa.

Portanto, a genealogia possibilita a constatação da duração da dominação política a partir de poucos grupos sociais, e ainda, consegue perceber as fontes de produção social das estruturas de poder e a sua reprodução, e a entender a unidade e coesão interna das elites (Ibidem, p.22-23), o que a simples biografia não conseguiria perceber, ampliando também a compreensão de como o "nascimento" potencializa a permanência de determinados indivíduos numa estrutura de poder. E ainda, a genealogia pode contribuir para o estudo da "circulação das elites" mapeando como grupos superiores vão também incorporando, mantendo e/ou trocando seus membros.

\section{A COLÔNIA DO ASSUNGUY. MAPEANDO CARACTERÍSTICAS DO PODER LOCAL}

Joaquim Severo Corrêa em 1861 foi nomeado diretor da colônia do Assunguy, e este foi o local em que fixou residência e a partir do qual foi eleito deputado provincial.

As colônias eram formadas no século XIX com o objetivo de atrair imigrantes, em especial europeus, para povoar as terras brasileiras preenchendo seu vazio demográfico, e assim repor a falta de mão de obra que não fosse escrava para a produção de alimentos ou para a grande lavoura. Elas eram formadas ou por iniciativa particular ou por incentivo e financiamento do Estado. No Paraná, a imigração foi também desde logo colocada no sentido de criar-se uma agricultura de abastecimento e consequentemente para a construção de estradas, ferrovias e de outros serviços públicos (BALHANA, MACHADO e WESTPHALEN, 1969, p.156-184).

A colônia do Assunguy foi um destes grandes investimentos realizados pelo governo Imperial, fundada em 1860, ao norte de Curitiba, em terras devolutas e emancipada em 1882, tornando-se Vila. Ela foi instalada para se tornar também o celeiro agrícola desta província, então carente de produtos básicos para a alimentação. Dividida em pequenas propriedades, teve muitas dificuldades de se desenvolver devido a estar longe dos centros consumidores, a possuir estradas sem mínimas condições de transporte da produção, e ao solo ser muito acidentado, fazendo com que muitos colonos abandonassem suas terras.

Sua estrutura administrativa contava com diretor, engenheiro, agrimensor, médico, enfermeiro, farmacêutico, capelão, feitor (ajudante), escrivão, professor, intérprete, enfim, funcionários imperiais e provinciais para acolher e organizar os novos moradores destas terras, em especial os imigrantes de várias partes da Europa. 
Os seus funcionários eram nomeados pelo Ministério da Agricultura, Comércio e Obras Públicas, a partir do Rio de Janeiro, vindo trabalhar nas respectivas colônias imperiais. O governo provincial do Paraná dava toda a estrutura necessária, inclusive com funcionários interinos. Era, portanto, um micro espaço de poder, praticamente autônomo das administrações das vilas, com organização baseada nas Leis e Decretos Imperiais, como o Regulamento para as Colônias do Estado de 1867, tendo como coordenador um diretor, que deveria prestar contas regularmente às autoridades competentes, provincial e imperial.

A referida colônia teve início em 1860 com cinco famílias de imigrantes alemães, e ao longo dos anos foram chegando também italianos, franceses, belgas, suíços, suecos, espanhóis, irlandeses. Foi chamada até de colônia de ingleses, mas era também de caráter misto, por aceitar colonos brasileiros. O relatório do presidente da província do Paraná, Frederico José Cardoso de Araújo Abranches, apresenta a seguinte estatística para a colônia no ano de 1874:

\begin{abstract}
A população da colônia do Assunguy que no ano de 1873 era de 1042 indivíduos, entre nacionais e estrangeiros, elevou-se no ano findo [1874] a 1345 provindo o acréscimo da entrada de 259 colonos de diversas nacionalidades e nascimento de 44 crianças, de que se deduz 17 óbitos que se deram (PARANÁ, 1875, estatística colonial).
\end{abstract}

E especifica que havia 645 brasileiros; 219 ingleses; 176 franceses; 134 alemães; 50 suíços; 41 irlandeses; 37 italianos; e 6 espanhóis (Idem).

Diante deste quadro histórico e desta dinâmica social, a colônia do Assunguy foi sendo estruturada e os colonos europeus e brasileiros foram se fixando nas terras previamente medidas e destinadas a eles.

Ao mesmo tempo, a organização política provincial no Paraná no período imperial, de acordo com BALHANA, MACHADO e WESTPHALEN (1969, p.144-151) era caracterizada pelo poder político nas mãos das famílias (ou oligarquias locais) porque eram detentoras de terras. E somente podiam votar cidadãos com renda igual ou superior a cem mil réis, que elegiam eleitores que iriam escolher os deputados à Assembléia Provincial, à Assembléia Geral e o Senador (quando necessário, pois era um cargo vitalício), sendo que este passaria pela aprovação do Poder Moderador, numa lista dos três mais votados. Portanto, eram dadas condições claras de desigualdade no acesso ao poder político. Mas seu controle trazia vantagens àqueles que o detinham e perseguição aos opositores. E ainda, as eleições paroquiais eram controladas pelos chefes locais apesar de algumas tentativas de reformas eleitorais. As eleições eram tranquilas se liberais e conservadores (partidos políticos deste período) entravam em acordos prévios e "pleiteadas" quando não fora possível o acordo. 
O que este estudo se pergunta, também, é se seria possível, em uma colônia para imigrantes, apesar da administração autônoma dos diretores, de lotes medidos em tamanhos igualitários, se reproduzir a tendência do poder político oligárquico e detentor de terras nestes novos ambientes? Para se responder a esta questão, se faz necessário analisar casos empíricos de construção e acesso ao poder político na localidade e buscar articular trajetória individual com contextos mais amplos da política provincial.

No próximo item, portanto, recupera-se a biografia de Joaquim Severo Corrêa, funcionário nomeado para ser diretor da colônia do Assunguy e que acaba se estabelecendo nesta localidade e em poucos anos se elegendo deputado provincial do Paraná. Objetiva-se Levantar sua biografia (através de documentos oficiais públicos) e mapear sua genealogia pode ajudar a entender as características da elite política do século XIX no Paraná.

\section{DADOS GENEALÓGICOS E BIOGRÁFICOS DE JOAQUIM SEVERO CORRÊA}

Na Genealogia Paranaense de Francisco NEGRÃO (1928, Vol.3 ${ }^{\circ}$, p.287) consta no item 6-2, o nome de Joaquim Severo Correia. Nascido a 21/jan/1833, casado com Emília Ribeiro de Campos²; Ele era filho do Comendador Manoel Francisco Correia Junior3 e Francisca Antonia Pereira Correia, que tiveram 14 filhos (Manoel Francisco - futuro Senador do Paraná, Joaquim Severo, Francisco Ferreira, Maria Bárbara, José Pereira, Américo Vespúcio, José Theodoro, João Ferreira, Leocádia Pereira, Pedro de Alcântara, Ildefonso Pereira - futuro Barão de Serro Azul, Urbano Sabino, Euphrasina e Francisca).

Maria Bárbara Correia (irmã de Joaquim Severo) casa com o Desembargador Agostinho Ermelino de Leão (várias vezes Vice-Presidente da Província do Paraná); Sua outra irmã Leocádia Pereira Correia [Guimarães] casa com o Coronel Joaquim Antonio Guimarães, filho dos Viscondes de Nácar (Visconde de Nácar, sr. Manoel Antonio Guimarães, por duas vezes Vice-Presidente da Província do Paraná, em 1873 e 1877, era casado com Clara Corrêa e segunda núpcias com Rosa Narcisa Corrêa, irmã de Clara,

\footnotetext{
2 "Emília Ribeiro de Campos, filha de Aurélio Ribeiro de Campos - o Velho - e de sua mulher Iphigência de Bittencourt, por esta, neta de Manoel José de Bittencourt e de sua mulher Anna Mauricia, com quem foi casado em Curitiba a 12/maio/1819; por ele, bisneta de José Correia de Bittencourt e de sua mulher Rosa Marianna, naturais de N.S. de Guadelupe, Ilha da Graciosa, Portugal; por Anna Mauricia é bisneta de Manoel Dias da Costa e de sua mulher Anna Joaquina dos Santos, naturais de Curitiba" (NEGRÃO, 1928, Vol. $3^{\circ}$, p.287). Emília Ribeiro terá uma segunda núpcias após o falecimento de Joaquim Severo Correia, com Manoel Francisco Gomes (NEGRÃO, 1930, Vol.5º, p.24).

3 "Comendador Manoel Francisco Correia Junior (n.1809, m.1857). Negociante. Proprietário de 3 sobrados em Paranaguá e 10 casas em Morretes e Porto de Cima. Possuía dois engenhos de soque de erva-mate e mais de 30 escravos" (OLIVEIRA, 2001, p.56). Chefe da guarda nacional do litoral, membro da imperial Ordem de Cristo, coletor de rendas gerais. Filho do Tenente-Coronel Manoel Francisco Correia.
} 
ambas da mesma família do Comendador Manoel Francisco Correia Junior); e Francisca Correia [Alves de Araújo], casa com o Comendador Antonio Alves de Araújo. E os filhos homens mais famosos do Comendador Manoel Francisco Correia Junior será Manoel Francisco Correia - Neto, Senador e Ministro do Império e Ildefonso Pereira Correia, o Barão de Serro Azul.

Pela Genealogia Parananaense percebe-se claramente as extensas e complexas relações e redes de parentesco de Joaquim Severo Corrêa. Seu pai e avô eram grandes comerciantes no litoral paranaense e políticos, suas irmãs casaram com outras importantes famílias curitibanas, também com poder econômico e político, e seus irmãos se destacaram como políticos e empresários. Ele próprio foi casado com mulheres de famílias tradicionais de Curitiba.

Por ser ele um homem público, é possível acompanhar, de maneira geral, através de documentos oficiais, os cargos e os incentivos públicos que recebe.

Em 1856, Joaquim Severo Corrêa e outros homens aparecem como ampliadores da estrada da Serrinha em Campo Largo (Jornal Dezenove de Dezembro, 16/abr/1856); e em 1857, com 24 anos, é nomeado pelo governo do Paraná como alferes da guarda nacional na localidade de Palmeira (Ibidem, 25/mar/1857) e logo depois, alferes na localidade de Morretes (Ibidem, 8/abr/1857);

Em 29/abril/1861 é nomeado como primeiro diretor efetivo da recém fundada colônia do Assunguy, encaminhado pelo presidente da província do Paraná, e depois confirmado pelo Ministério da Agricultura, Comércio e Obras Públicas, do Rio de Janeiro (PARANÁ, 19/abr/1861, p.10)4. Acredita-se que ele teria sido nomeado para este importante cargo por influência política, afinal, a maioria dos diretores vinha da província do Rio de Janeiro (ALVES, 2011); Mas em 28/fev/1862 é exonerado do cargo de diretor da colônia e em seu lugar entra o engenheiro de origem alemã, Gotlieb Wieland (BRASIL, 1862).

Severo Corrêa fica apenas 10 meses como diretor da colônia. Afinal, a rotatividade dos diretores das colônias imperiais brasileiras era muito comum. De acordo com Luchese (2009)5, geralmente os diretores ficavam pouco tempo na administração, sendo trocados constantemente, bem como os demais funcionários. Mas diferente do que acontecia quando um diretor era exonerado, em que este era transferido de colônia ou para outra função pública, Severo Corrêa irá permanecer na localidade. Terá lotes (chamados também de "prazos") e tornar-se-á comerciante. Irá,

\footnotetext{
4 Fala do presidente da província do Paraná Dr. Antonio Barbosa Gomes Nogueira: "Foi nomeado e já prestou juramento, o diretor efetivo do núcleo colonial do Assunguy Joaquim Severo Corrêa".

5 Terciane Ângela Luchese (2009) pesquisou as "relações de poder" entre colonos e diretores das colônias imperiais para imigrantes Conde d'Eu, Dona Isabel, Caxias e Alfredo Chaves, no Rio Grande do Sul, no período de 1875 a 1899.
} 
portanto, se fixar no Assunguy, espaço destinado especialmente a colonos europeus e brasileiros. Quando deixou a direção em 1862, a colônia possuía apenas 85 pessoas.

No diário oficial do Império, de 18/fev/1864, exigia-se informações sobre a qualidade do algodão colhido por Joaquim Severo Corrêa, na colônia do Assunguy, PR (BRASIL, 1864). Percebe-se que este já possuía financiamento público para suas plantações.

Em 1866 é nomeado capitão para o batalhão de artilharia da guarda nacional,

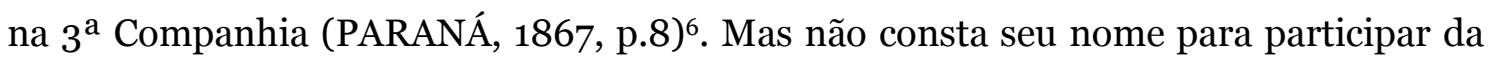
Guerra do Paraguai, entre 1864 e 1870.

Ainda em 1866:

Por portaria de 4 de junho determinei se fizesse a roçada de 50 palmos de largura, na extensão de 7763 braças, a razão de 80 réis a braça linear, nas secções $2^{\mathrm{a}}, 3^{\mathrm{a}}$ e $4^{\mathrm{a}}$ da estrada da colônia. Em 27 de junho [1866] ordenei o pagamento destas obras empreitadas pelo capitão Joaquim Severo Corrêa, depois de recebidas pelo diretor da colônia [Sr. Manoel Antonio Ferreira] (PARANÁ, 1867, p.16).

Neste mesmo ano ele era suplente do subdelegado na colônia do Assunguy (PARANÁ, 1867b, Quadro n. ${ }^{\circ}$ 2). Aqui se apresenta suas atividades como capitão de batalhão, de força policial na colônia e como empreiteiro.

Em 1867, consta seu nome e de Manoel Antonio Ferreira (então diretor da colônia do Assunguy), no livro The empire of Brazil at the Paris international exhibition of 1867 na qual, junto com outros paranaenses e expositores do Brasil, apresentam os seguintes produtos em Paris: nankeen cotton, fibres of guapeba, cipó sumo in powder, caninha spirit [algodão de nanquim, fibras de guapeba, cipó de sumo em pó, caninha].

Manoel Antonio Ferreira7, paranaense, era um importante empreiteiro e político na província do Paraná, com obras na região de Curitiba, em especial ao longo do rio Barigui, chegando a ser vice-presidente desta província em 1863, deputado provincial em inúmeras legislaturas, membro da câmara de Curitiba, coletor e pertencente ao partido Conservador, ligado aos comerciantes e industriais em oposição à aristocracia agrária dos Campos Gerais, do partido Liberal.

Em 1868 tem-se uma situação de conflito entre Severo Corrêa e o então diretor da colônia do Assunguy, o francês Julio Luis Parigot. De acordo com Parigot, os senhores Joaquim Severo Corrêa, coronel Manoel Antonio Ferreira, e Miró possuíam

\footnotetext{
${ }^{6}$ Chamado de "tenente Joaquim Severo Corrêa".

7 Sobre Manoel Antonio Ferreira, verificar o site Colégio Brasileiro de Genealogia. O Paraná em 1879. Disponível em: http://www.cbg.org.br/arquivos genealogicos p 05.html. Acesso 28/maio/2011. Manoel Antonio Ferreira era descendente da família de Baltazar Carrasco dos Reis, bandeirante e senhor de sesmaria do Rio Barigui, em Curitiba, em 1661 (OLIVEIRA, 2001, p.12).
} 
terrenos no centro da colônia, e os colonos tinham de ser instalados a distâncias cada vez maiores de seu centro administrativo, inclusive dificultando que os filhos destes colonos pudessem frequentar a escola (PARANÁ, 1866 a 1872, Códice 380, APP). Este desentendimento se deve principalmente porque em 10 de janeiro de 1868 Severo Corrêa requereu ao governo do Paraná poder comprar mais terras na colônia em que residia (onde já possuía dois "prazos", sendo um urbano e outro suburbano). Um dos lotes que desejava comprar era na distante localidade de Socavão, caminho para a vila de Castro, que relatava ser para o desenvolvimento do comércio local (AP 0294, p.048, APP); mas o diretor Parigot se posicionou contra estas aquisições.

Nesta colônia para imigrantes já se tem exemplos de concentração de terras por parte de alguns indivíduos, como Severo Corrêa e Manoel Antonio Ferreira, que como visto, possuíam ligações comerciais e políticas, e Miró, provavelmente o negociante de Morretes. O comendador José Miró de Freitas que em 1859 requereu e foi permitido pelo governo imperial, a "comprar, a real por braças, oito lotes das terras do $2^{\circ}$ território medido" (PARANÁ, 1859, p.8-9), no centro da colônia.

E em 28 de dezembro de 1868, Severo Corrêa estava na relação das autoridades policiais, nomeado para toda a região de Votuverava (PARANÁ, 1869b, Quadro de autoridades policiais nomeadas).

Para o biênio de 1872 e 1873 foi eleito deputado provincial do Paraná (FERREIRA, 1996, p.115). Aqui se tem o auge de sua carreira pública. Mesmo morando na distante colônia, mobilizou recursos suficientes para conseguir ser deputado.

Em 31/maio/1873 foi nomeado comandante do $6^{\circ}$ batalhão de infantaria de Votuverava (PARANÁ, 1874, p.7) ${ }^{8}$. E fez a proposta junto com Lino de Souza Ferreira para construir toda a estrada da capital a colônia do Assunguy (PARANÁ, 1874, p.35). Novamente destaca-se sua atuação como membro da guarda nacional e empreiteiro.

Em outubro de 1873, o engenheiro inglês Bigg-Whiter teria se hospedado na casa de Severo Corrêa, na colônia do Assunguy, na qual o chamou erradamente de senhor Serivero, e que Temístocles Linhares também traduziu de forma equivocada como casa do senhor Silveira (BIGG-WHITER, 1974, p.368). Bigg-Whiter destacou a grande acolhida de Severo a ele e seus ajudantes. Mas o que mais lhe chamou a atenção foi que teria visto em seu estabelecimento comercial um grande livro de contas, "onde estavam escritos provavelmente os nomes dos colonos adultos do sexo masculino que estiveram no Assunguy", provocando sua admiração. Eram colonos compradores e devedores do comércio de Severo. Isto destaca a importância de seu comércio na localidade e também demonstra que mesmo como deputado provincial não deixou de morar na colônia.

${ }^{8}$ Chamado de "major Joaquim Severo Corrêa". 
De acordo com Luchese (2009, p.96), "o grupo de comerciantes das colônias, após os primeiros tempos, passaram a exercer influência nos núcleos, à medida que acumulavam capital", deixando de vender produtos aos colonos "maus pagadores", controlando preços, exigindo dos diretores o pagamento dos subsídios para os colonos para que estes pagassem suas dívidas em seus comércios, etc.

Severo Corrêa foi reeleito deputado provincial do Paraná para os anos 1874 e 1875 (FERREIRA, 1996, p.116). Quanto a seu partido político, é provável que fosse membro do partido Conservador, na qual era filiado Manoel Antonio Ferreira e também seu irmão Ildefonso Pereira Correia.

Em 1874, no relatório do cônsul inglês Lennon Hunt sobre a colônia do Assunguy, na qual foi verificar pessoalmente as más condições de vida dos colonos ingleses, tem-se a seguinte denúncia:

Causou-me grande surpresa descobrir que nenhum dos colonos teve permissão para instalar-se próximo ao núcleo colonial; todas essas terras, que são notavelmente boas, foram cedidas a pessoas influentes na Província. Elas começam perto da porta da casa do governo e nenhum acre delas está sendo cultivado. Oito ou nove seções, de 300 acres cada, pertencem a um senhor Miró, que não é um residente. Oito seções, da mesma extensão cada, pertencem a um senhor Rocha, também não residente, e um trecho de oito seções, da mesma extensão cada, pertencem ao senhor Severo Corrêa, que reside na Colônia, mas que não cultivou nenhuma parte de sua terra. Estes fatos demonstram um estado de coisas que dificultou o sucesso da Colônia desde o seu começo. As terras mais próximas e melhores foram apropriadas por pessoas que não as cultivaram, o que tornou inevitável o assentamento dos colonos em distâncias relativamente grandes do centro. (Cônsul Lennon HUNT, 1874, in MONUMENTA, 1998, p.24).

Denúncia praticamente igual à feita pelo diretor Parigot em 1868. Porém, agora aparecendo o nome do senhor Rocha no lugar de Manoel Antonio Ferreira e especificando o tamanho de suas propriedades e localização. E o relatório ainda destacava que "um dos principais armazéns [na colônia] pertence ao senhor Corrêa, o cunhado do Vice-Presidente"9 (Ibidem, p.32). Porém, não menciona seu cargo como deputado. E de acordo com o colono inglês Cornelius Marsh, havia uma ordem do presidente da província que o diretor deveria comprar tudo para a colônia do senhor Corrêa (Ibidem, p.6o). Enfim, se percebe que Severo Corrêa possuía um amplo controle do poder local nesta colônia, isto tudo independente do diretor de colônia que fosse nomeado.

Em 1875, tem-se a seguinte nota no relatório do presidente da província do Paraná, Adolpho Lamenha Lins: "tendo falecido o prestimoso e distinto tenente coronel

9 Poderia estar se referindo aos vice-presidentes da província do Paraná, Manoel Antonio Guimarães (Visconde de Nácar) ou a Agostinho Ermelino de Leão, ambos seus cunhados. 
Joaquim Severo Corrêa, deputado eleito nessa ocasião [7/set/1875], deve-se proceder a eleição de um deputado provincial que o substitua" (PARANÁ, 1876, p.2-3).

Fato de pesar também relatado pelo então diretor da colônia do Assunguy, Pedro de Alcântara Buarque, dizendo que ficou vaga a função de inspetor de quarteirão $0^{10}$ que realizava de modo notável o senhor Severo Corrêa.

O auge de sua carreira foi a atividade como deputado provincial do Paraná, mas interrompida pelo seu falecimento com apenas 42 anos. O casal Severo Corrêa e Emília Ribeiro de Campos não tiveram descendentes. E ela se casou novamente com Manoel Francisco Gomes.

Na colônia para imigrantes do Assunguy, um indivíduo mobilizava recursos suficientes para qualificá-lo como "elite” econômica, política e militar. E é um exemplo concreto de como elites políticas locais no final do século XIX no Paraná agiam e se consolidavam no poder, através do domínio de terras, comércio, guarda nacional e obras públicas. E por pertencer a uma ampla rede de parentesco, constituída por famílias históricas do Paraná, sendo ele mesmo um de seus membros.

\section{Quadro 1 - Joaquim Severo Corrêa}

\begin{tabular}{|c|c|c|}
\hline & & $\begin{array}{c}\text { REDE DE PARENTESCO: } \\
\text { Neto, filho e irmão de } \\
\text { importantes comerciantes e } \\
\text { políticos do litoral e capital } \\
\text { paranaense (Correia). }\end{array}$ \\
$\begin{array}{c}\text { Possuía terras, comércio e } \\
\text { era empreiteiro em obras } \\
\text { públicas. }\end{array}$ & $\begin{array}{c}\text { Colônia do Assunguy } \\
\text { Paraná }\end{array}$ & $\begin{array}{c}\text { Cunhado, com a família Leão, do } \\
\text { Visconde de Nácar - Guimarães, e } \\
\text { Alves Araújo, por parte do } \\
\text { casamento de suas irmãs. } \\
\text { Casado com a família Ribeiro de } \\
\text { Campos e Bittencourt. }\end{array}$ \\
\hline $\begin{array}{c}\text { GUARDA NACIONAL } \\
\text { Cores, Capitão, Tenente, } \\
\text { batalhão e Majonte de }\end{array}$ & JOAQUIM SEVERO & \\
$\begin{array}{c}\text { E na colônia: Subdelegado e } \\
\text { Inspetor de Quarteirão }\end{array}$ & CORREA & \\
\hline
\end{tabular}

Seu irmão de maior destaque na economia e política paranaense, no final do século XIX, foi o Barão do Serro Azul, Ildefonso Pereira Correia.

10 Inspetores de Quarteirão "eram indivíduos nomeados pelo delegado de polícia e encarregados de garantir a moral e os bons costumes entre a população de seu quarteirão, através de uma contínua ação vigilante. Residiam em cidades, vilas ou colônias, estendendo o policiamento até os lugares mais distantes. Sua importância crescia quando o descrédito para com a Polícia regular era confirmado, e quando a ameaça transparecia aos cidadãos, assustados com a presença de imigrantes nem sempre contidos e ordeiros" (LAMB, 1999, p.80). 
Ildefonso nasceu em 1849. Foi um dos principais empresários do Paraná na época, sendo comerciante e proprietário de engenhos de erva-mate, serraria, impressora paranaense, criou o Banco Mercantil Industrial do Paraná em 1889, primeiro diretor da Associação Comercial do Paraná, fundada em 1890, participou da criação do Clube Curitibano, entre outras atividades. Como político foi presidente da câmara de Curitiba, deputado provincial, vice-presidente da província, membro do partido Conservador. Foi fuzilado em 1894 após a retomada de Curitiba pelos florianistas por ser considerado traidor na Revolução Federalista (COSTA, 1981; OLIVEIRA, 2001, p.58).

Ildefonso Pereira Correia recebeu o título de barão no dia 8 de agosto de 1888 . David CARNEIRO (1981, p.69) diz que o título dado por D. Pedro II ao Comendador Ildefonso, teria sido "de sua própria escolha”, sem saber que já existia outro barão do Serro Azul no Rio Grande do Sul, mas não explica o motivo pelo qual Ildefonso o escolheu. É provável, acreditamos, que "Serro Azul” seja em homenagem ao seu ilustre irmão morador na Colônia do Assunguy. Pois, em 02 de abril de 1872 a colônia foi elevada a categoria de freguesia, com a denominação de Serro Azul e invocação de Nossa Senhora da Guia; em 1875, faleceu Severo Corrêa. Em 1882 é elevada à categoria de vila do Assunguy, mas depois, em 1885, passa a ter a denominação de vila de Serro Azul. Quando Ildefonso Correia recebeu este título, uma comitiva de Serro Azul, liderada pelo Padre Celso Cezar Itiberê da Cunha (futuro Monsenhor Celso), veio felicitar o novo barão. Ildefonso também tinha outras ligações com a cidade de Serro Azul. Consta que em 1 de Novembro de 1884, a imagem de Nossa Senhora da Guia, padroeira da localidade, teria sido doada pela d. Maria José Correia, mais tarde Baronesa do Serro Azul. A imagem foi colocada na nova igreja que nesse dia também foi inaugurada e benzida (NEGRÃO, 1954, p.683). Ildefonso e sua esposa ajudavam muito esta localidade, "procurando desenvolver as suas vias de comunicação e fazendo doações para a igreja local” (COSTA, 1981, p.65).

\section{CONSIDERAÇÕES FINAIS}

A presente pesquisa empírica avaliou as condições de ação e reprodução de um membro da elite local paranaense. Investigou-se um homem real, suas nomeações, suas conquistas, num determinado momento histórico e lugar específico. Alguém que reproduziu de forma exemplar os mecanismos de controle utilizados pela elite a qual pertence, através do domínio de terras, comércio, guarda nacional e poder político, para manter seus privilégios. 
Porém, apenas a biografia era insuficiente para compreender outras condições que faziam dele uma pessoa com determinadas vantagens sociais frente a seus semelhantes. Vantagem caracterizada por ser ele membro de famílias históricas do Paraná, como demonstra a genealogia, e estar inserido, portanto, em complexas redes de parentesco.

Gaetano Mosca percebia também no contexto histórico italiano, e na formulação da teoria das elites, como esta força social do nascimento estava presente e era visível ao analista político. Já, a preocupação de Vilfredo Pareto, quanto à “circulação de elites", era identificar como os indivíduos naturalmente "superiores" tendem a buscar um equilíbrio social, combinando elementos das diversas classes sociais, evitando assim "revoluções". Para o século XIX, percebe-se pela genealogia como as elites vão, ao mesmo tempo, impondo seu modelo de domínio, mas também assimilando e mesclando novos elementos, como pelo casamento.

Joaquim Severo Corrêa, entretanto, não deixa de ser um exemplo de intenso trabalho, de desbravamento em novas terras, de avanço em "fronteiras", assim como fizeram seus antepassados, por buscar construir sua vida e de sua família numa localidade frágil e ainda por se desenvolver, local chamado também de "sertões do Assunguy”. Mas não deixa igualmente de ser um exemplo de como um indivíduo da "elite" leva para uma nova localidade toda uma estrutura de dominação.

Mapear a biografia e genealogia da "elite" revela as características que realmente os diferenciam de outros indivíduos no desempenho de seu papel social. Isto num ambiente em que a princípio deveria ser específico para a igualdade, que eram as colônias para imigrantes, na qual todos deveriam receber lotes de terras em tamanhos iguais, mesmos incentivos governamentais e os mesmos salários para os trabalhos públicos.

\section{REFERÊNCIAS BIBLIOGRÁFICAS}

ALVES, Alessandro Cavassin. Análise prosopográfica dos diretores de uma colônia imperial para imigrantes no Paraná, Século XIX. XXVI Simpósio Nacional de História. São Paulo: USP, 2011.

http://www.snh2011.anpuh.org/simposio/programacao?ID SIMPOSIO=602 (Acesso 30/07/2011).

BALHANA, A.P.; MACHADO, B.P.; WESTPHALEN, C.M. História do Paraná. Vol.1. Curitiba: Grafipar, 1969.

BIGG-WITHER, Thomas P. Novo caminho no Brasil Meridional: a Província do Paraná, três anos de vida em suas florestas e campos. 1872/1875. Rio de Janeiro: J.Olympio; Curitiba: UFPR, 1974, Curitiba: Imprensa Oficial do Paraná, 2001. BOBBIO, Norberto. Teoria das Elites. In: BOBBIO, N., MATTEUCCI, N., PASQUINO, G. Dicionário de Política. Brasília: Editora da Universidade de Brasília, $12^{\mathrm{a}} \mathrm{ed}$., 2004 . 
BOTTOMORE, T.B. As Elites e a Sociedade. Tradução Otávio Velho. Rio de Janeiro: Zahar Editores, 1965.

BOURDIEU, Pierre. A ilusão biográfica. In: FERREIRA, Marieta de Moraes \& AMADO, Janaína. Usos \& abusos da história oral. Rio de Janeiro, FGV, 1986, (p.183-191).

CARNEIRO, David. Perfil histórico da Associação Comercial do Paraná e galeria dos presidentes. Curitiba: Repro-set, indústria gráfica Ltda, 1981.

CHARLE, C. História das elites e método prosopográfico. In: HEINZ, F. M. (org.). Por outra história das elites. Rio de Janeiro: Fundação Getúlio Vargas, 2006.

COSTA, Odah Regina Guimarães. Ação empresarial do Barão de Serro Azul. Subsídios para o estudo da industrialização no Paraná. Curitiba: Secretaria de Estado da Cultura e do Esporte, 1981.

FERREIRA, João Carlos Vicente. O Paraná e seus municípios. Maringá, PR: Memória Brasileira, 1996.

GRYNSZPAN, Mario. Ciência, política e trajetórias sociais: uma sociologia histórica da teoria das elites. Rio de Janeiro: Editora FGV, 1999.

. A Teoria das Elites e sua Genealogia Consagrada. BIB, Rio de Janeiro, n.41, pp.35-83, $1^{\circ}$ semestre de 1996.

HEINZ, Flávio M. (org.). Por outra história das elites. Rio de Janeiro: Fundação Getúlio Vargas, 2006.

HOLLANDA, Cristina Buarque de. Teoria das Elites. Rio de Janeiro: Zahar, 2011.

LOPES, José Carlos Veiga. Aconteceu nos Pinhais: subsídios para a história dos municípios do Paraná tradicional do Planalto. Curitiba: Editora Progressiva, 2007.

LAMB, Roberto Edgar. Uma Jornada Civilizadora: imigração, conflito social e segurança pública na Província do Paraná - 1867 a 1882. $2^{\text {a }}$ ed. Curitiba: Aos Quatro Ventos, 1999.

LOVE, Joseph L. e BARICKMAN, Bert J. Elites Regionais. In: HEINZ, F. M. (org.). Por outra história das elites. Rio de Janeiro : Fundação Getúlio Vargas, 2006.

LUCHESE, Terciane Ângela. Relações de Poder: Autoridades Regionais e Imigrantes Italianos nas Colônias Conde d'Eu, Dona Isabel, Caxias e Alfredo Chaves: 1875 a 1889. Curitiba: Editora CRV, 2009.

MONUMENTA. Imigração para o Brasil. Apresentação Magnus Roberto de Mello Pereira e Relatório sobre a colônia Assunguy, apresentado a ambas as casas do Parlamento por Ordem de Sua Majestade. Londres, 1875. Curitiba, Aos Quatro Ventos, 1998.

NEGRÃO, Francisco. Genealogia Paranaense. Vol. $3^{\circ}$ e Vol. $5^{\circ}$. Impressora Paranaense, 1928, 1930.

NEGRÃO, Francisco. Efemérides Paranaenses. $2^{\circ}$ Volume, julho-dezembro. Separata da edição especial da Revista do Círculo de Estudos Bandeirantes no $25^{\circ}$ aniversário de sua fundação. Setembro de 1954. 
OLIVEIRA, Ricardo Costa de. O silêncio dos vencedores. Genealogia, classe dominante e estado do Paraná. Curitiba: Moinho do Verbo, 2001.

. A genealogia como metodologia de análise das estruturas de desigualdade e estratificação social. XV Congresso Brasileiro de Sociologia, Curitiba: UFPR, 2011.

http://www.sistemasmart.com.br/sbs2011/arquivos/29 $6 \begin{array}{lllll}6 & 2011 & 22 & 3 & 3 . p d f\end{array}$ (Acesso 15/08/2011).

PERISSINOTTO, Renato; CODATO, Adriano; FUKS, Mario; BRAGA, Sérgio; (Org.). Quem governa? Um estudo das elites políticas do Paraná. Curitiba: Editora UFPR, 2007.

Site institucional:

Arquivo Público do Paraná. Disponível em: http://arquivopublico.pr.gov.br Link: Pesquisa On-line:

PARANÁ. Relatórios dos Presidentes da Província do Paraná, 1854 a 1882. Disponível em:

http://www.arquivopublico.pr.gov.br/modules/conteudo/conteudo.php?conteudo=44 Documentos Oficiais

BRASIL. Relatório das Terras Públicas e da Colonização. Ministério da Agricultura, Comércio e Obras Públicas, Rio de Janeiro. 28/fev/1862.

BRASIL. Diário Oficial do Império. Ministério da Agricultura, Comércio e Obras Públicas, Rio de Janeiro. 18/fev/1864.

PARANÁ. Registro de correspondências dirigidas à Presidência pelos diretores da Colônia do Assunguy entre 1866 e 1872. Códice 380. DEAP.

The empire of Brazil at the Paris international exhibition of 1867. Rio de Janeiro: Printed by E. \& H. Laemmert. 61B, Rua dos Inválidos, 1867. Disponível em: http://books.google.com.br/books?id=MsyKBtdIb10C\&printsec $=$ frontcover $\& d q=$ The + empire + of + Brazil + at + the + Paris + international + exhibition + of $+1867 \& \mathrm{~cd}=1 \# \mathrm{v}=$ onepage $\underline{\text { qq } \& \mathrm{f}=\text { false }}$ 